Original Research Paper

\title{
Concretes Resistance of Yam a Great Persistence
}

\author{
${ }^{1}$ Hossein Gholami, ${ }^{2}$ Majedeh Haeri-Hamedani, ${ }^{3}$ Mohsen Ghane \\ and ${ }^{4}$ Kaveh Ostad-Ali-Askari \\ I*Department of Civil Engineering, Isfahan (Khorasgan) Branch, Islamic Azad University, Isfahan, Iran \\ ${ }^{2}$ Department of Water Engineering, College of Agriculture, Isfahan University of Technology, Isfahan, Iran \\ ${ }^{3}$ Civil Engineering Department, South Tehran Branch, Islamic Azad University, Tehran, Iran \\ ${ }^{4}$ Department of Civil Engineering, Najafabad Branch, Islamic Azad University, Najafabad, Iran
}

Article history

Received: 16-02-2019

Revised: 03-05-2019

Accepted: 30-09-2019

Corresponding Author:

Mohsen Ghane

Civil Engineering Department,

South Tehran Branch, Islamic

Azad University, Tehran, Iran

Email: mohsenmohsengh@gmail.com

\begin{abstract}
Today all distinguish the position of earthquake withstanding of constructions in seismic-vulnerable zones. With respect to this opinion that current concrete constructions are usually considered and constructed depend on earliest rules lacking examining the result of seismic powers and the novel rules don't guess any shake, so, these structures must be persistence capability. Investigation on standards of HPFRCC substantial as one of the most appropriate limited persistence approaches of concrete constructions member has a distinct ineffectiveness. we can apply dissimilar approaches to maintenance destroyed concrete structures by the seismic or to complete shake persistance of current concrete structures. There are two procedures of applying steel sheets and FRP sheets for concrete memberships reinforcement or renovation. Each of these two approaches is comprehension of these resources with concrete and absence of organization in their way and features. First scholars have exposed that the recent HPFRCC substantial that mostly is a concrete with a high persistance with steel, glass, aramid and carbon yam has a appropriate interactive organization with concrete and can rise concrete persistance frame the opinion of assessment of bending and portional as these two other constituents. In this paper, we attempt to compare concretes which one consist of above yam frame the point of opinion of pressure and tonsorial persistance to make concrete sheets with high persistance entirely, that at last easy's receptacle of steel sheets had improved consequences of pressure and tonsorial persistance to generate these sheets into other models.
\end{abstract}

Keywords: Maintenance, Concrete Sheet, Steel Yam, Glass, Agamid Yam

\section{Introduction}

Significant experiential work was completed to check the mechanical constancy of fiber-reinforced insubstantial protected concrete (Tareq et al., 2019). While frame the opening of making concrete, there is a slight development in its construction, but a massive range of concrete procedure really displays us that a lot of substantial (inexpensive, available, tough, ...) dominates its other facts. In the last few periods, to make similar situations and decrease concrete frangibility faintness some deal, they apply brittle and long fibres that sprinkle in all of the concrete mass consistently and cluttered (Heng-Lei,2019).
The new great-performance substantial is examined as brittle concrete was extended with the purpose of eliminating the likely for legitimate sections of cracked concrete when building is impacted by a lively load, like the detonation power from a extremist transportation explosive (Alyaa et al., 2018).

\section{Reinforced Concrete to Steel Yam}

In new centuries there has been completed massive investigations and they attemped to improve concrete features by accumulation steel yam (Wenting et al., 2019). At current period, reinforced concrete with steel yam is measured as one of the recent structure resources, vary and with some conditions that are single from the 
idea of assessment of persistance, tensorial capability and behavior in contradiction of fracture. Chief resources of reinforced concrete with yam are similar normal concretes (Aram et al., 2008). Usage of Yam Steel resources for strengthening and conservation of organizational memberships has become a increasingly general region of examination and usage in the previous period (Chen and Qiao, 2015). But, the process is until now to become a usual practice due to a quantity of economic and strategy linked substances. From a organizational specialists position, important apprehension about the achievement and safety of this process is the likely of fragile debonding fractures. Such failure, unless often inspected in the project procedure, may particularly decrease the advantage of the invigorating or repair usage (Chehab et al., 2018). In recent centuries, there has been an concentration of investigation efforts on the classification and showing of yam steel. This paper provides a review of the development attained in this region about usages to steel yam. The significance brittleness with little ductile stability and tension dimensions of great-stability concrete can become the extra of steel yam. This paper examined the automatic qualities of great-stability steel yam (Atis, 2013). Constancy patterns were chosen to guess the pressure and intense ductile constancies and modulus of interruption of the fiber-reinforced concrete. This study inspects the optimization of steel yam respect on over-all automatic structures. The numerous dimensions are of steel yam contributed to numerous motorized landscapes, at smallest to a numerous grade (Aprianti, 2017). The crack structures and the active structures will be inspected for the fibers concrete with fine over-all powered structures of steel yam. steel yam is increasingly existence used daytime as a physical substantial (Bogas et al., 2016). The consequence of steel yam adding to concrete on some of the main factors specifically top pressure, straining at top pressure, the rigidity of concrete and the qulaification of the pressurecompressive curvature is inspected (fThere chances a respectable association between the empirical significances and those figured reagrd on the rational prototypical. Calculations are also recommended to quantity the consequence of steel yam on pressure stabiity, straining at top stress and the rigidity of concrete in relations of steel yam components (Sirca Jr et al., 2018).

Resources that have a great excellence are practical in yam concrete and toughened concrete conditions are addition of concrete employing approaches and density of concrete cement (Berto et al., 2015). In this review, ordinary systems, waved webs or extended and thin frameworks can't be measured as single and extended yam (Aram et al., 2008). The impact of yam concrete on stopping crash broadcast in concrete was inspected. The concrete yam construction displays better-quality constancy, elasticity and fire persistance. A main symbol of this sort of construction is the bond association presented between steel and concrete, which directly rises the load dimensions of the construction (Karakurt and Bayazit, 2015). The matter of steel erosion in concrete constructions in the penetrating situation has been an fascinating feature in conditions of corrosion and civil engineering resources which it recovers with steel yam. Furthermore, steel yam is impacted by numerous components, which lastly owing to the stability of reinforced concrete constructions and the rise of facility lifetime. This paper is depend on an empirical education on the last load conduct of steel yam in the strategy (Aldaood et al., 2016). The empirical significances for distortions steel yam, for pressure privileges and for last constancies were create to be in enjoyable arrangement with the consistent standards can forecast by finite element investigation. Steel yam is practical widely in contemporary constructions. enormous study on steel yam in which physical steel piece is covered in concrete has been approved out. it can examine steel yam is assumed with status on empirical and technical work (Lawrence, 1974).

\section{Yam Concrete Benefits}

The conduct of compound steel-concrete yam at great temperatures is a significant problem. steel yam fundamentals are being inspected worldwide as a whole sort of reinforcement for concrete constructions (Hanjari et al., 2011). It can apply a finite element database for the nonlinear investigation of steel-concrete yam. The database can inspect the nonlinear conduct of concrete, steel yam. it occasionally applies some examples of mechanical schemes that apply steel yam in bridge constructions and compound rebars as strengthening to concrete. Steel yam may be used when ecological contrary circumstances destroy the steel in reinforced concrete (Islam et al., 2018). The great precise stability of steel-concrete yam is vital when investigative the supportive cables of suspension bridges. This paper considers advanced networks which let steel and concrete yam constructions to be encountered comprehensive (Dongsheng et al., 2019)

\section{Aramid Yam}

Aramid yam that is presented about 1970, are biological combination of carbon, hydrogen, oxygen and nitrogen. Small concentration and great tensorial constancy in these yams reason to establish a outstanding construction to the impression with a pressure about half of the carbon yam (Wang and Petru, 2019). Aramid yam at primary is completed to substitute steel in outspread fatigues and then 
have originated another application.one of the greatest effective Aramid yam practice is rised resistant cover (Aram et al., 2008).

The Aramid yam has a rounded cross-segment, is resilient at temperatures (Yildirim et al., 2015). But important wants to improve aramid-epoxy bond, the bond stages got between aramid yam and epoxy matrices are fewer than finest for some practices. Configuration of the aramid yam structure and biochemical structures and the interfacial automatic pressures are in responsibility of the lack of achievement in rising aramid-epoxy bond level (Penttala and Al-Neshawy, 2002). A sign to enhancing the aramid-epoxy penetrating is a elementary understanding of the interfacial instruments by which fiber and matrix collaborate (Wang et al., 2017). There is an important amount of broadcasts on aramid yam and their compounds. This paper inspects some of the procedure related to aramid yam connection instruments (Mehta, 1980). The correlation between form and automatic structures for a sequence of well-featured aramid yam has been distinct. The aramid yam was shaped under a variety of dispensation circumstances (Allen, 1983). It has been an display that the automatic constructions of the aramid yam are capable by the aramid yam construction. Figure 1 shows Failure modes: (a) Beginning of concrete crushing; (b) Concrete crushing ( C16-N); (c) FRP bar rupture and concrete crushing (G16-P); (e) GFRP bar rupture (G16-N) (Dong et al., 2019). Figure 2 shows FRP Constituents (ISIS Canada-01, Reinforcing concrete structures with fiber reinforced polymers; Tareq et al., 2019). Figure 3 shows CFRP tensile static and fatigue resistance (Lawrence, 1974; Tareq et al., 2019). Figure 4 shows Pictures of the CFRP strips after pull-out tests (Alyaa et al., 2018; Tareq et al., 2019).
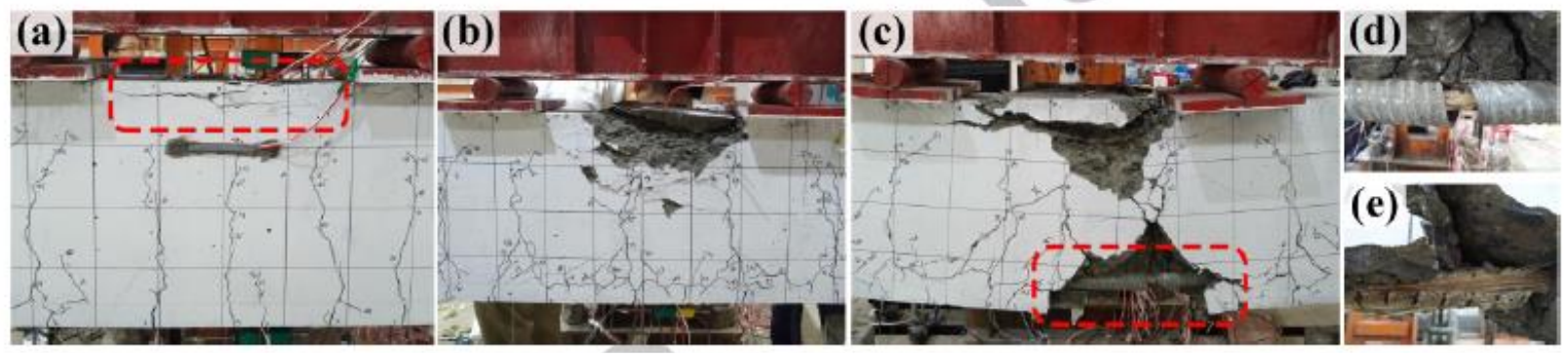

Fig. 1: Failure modes: (a) Beginning of concrete crushing; (b) Concrete crushing ( C16-N); (c) FRP bar rupture and concrete crushing (G16-P); (e) GFRP bar rupture (G16-N) (Dong et al., 2019)

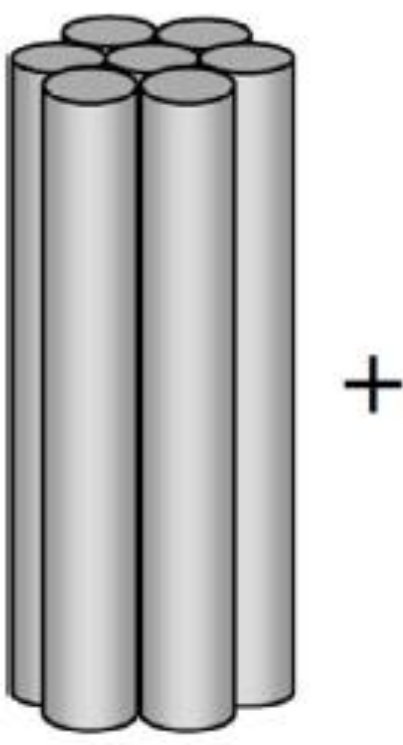

FIBRES
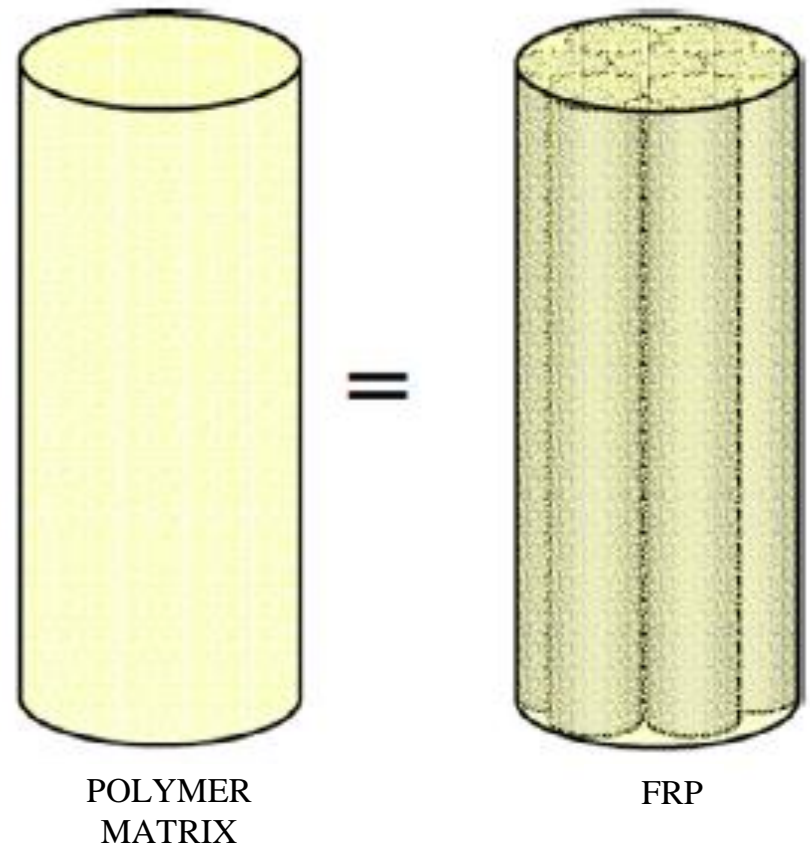

FRP

Fig. 2: FRP Constituents (ISIS Canada-01, Reinforcing concrete structures with fiber reinforced polymers; Tareq et al., 2019) 


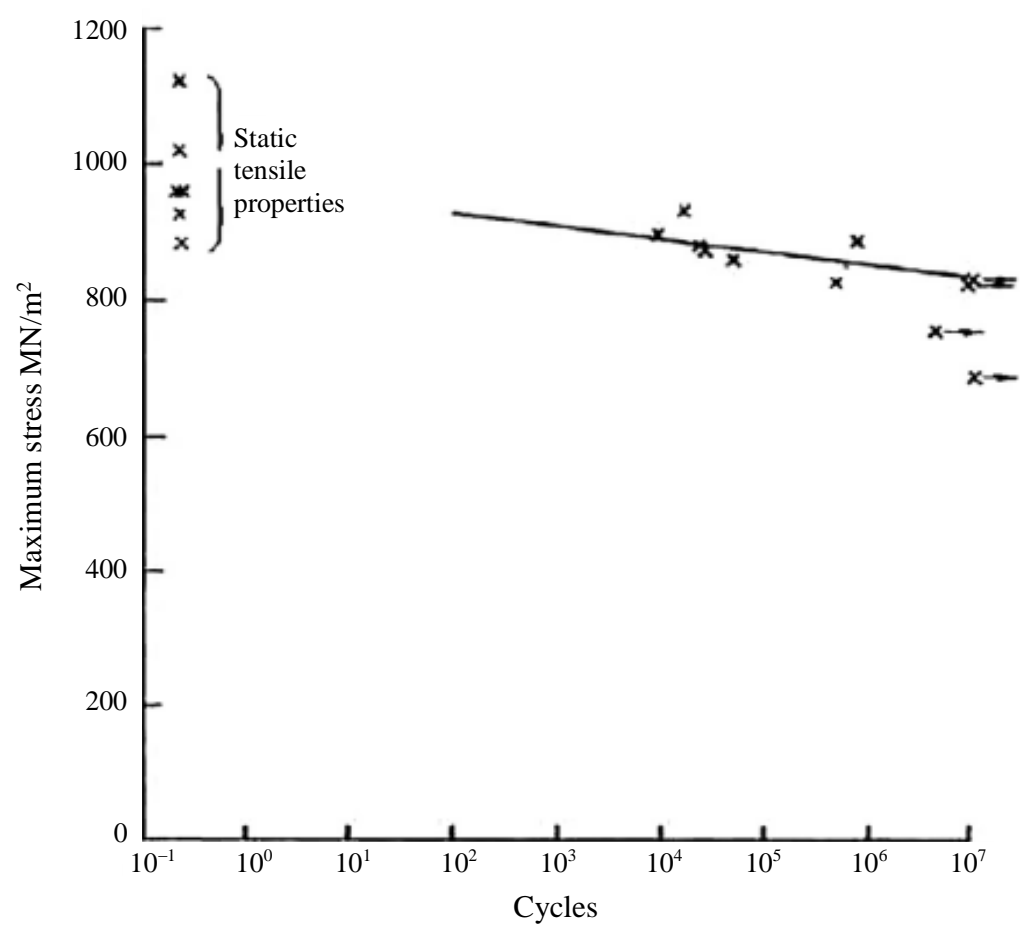

Fig. 3: CFRP tensile static and fatigue resistance (Lawrence, 1974; Tareq et al., 2019)

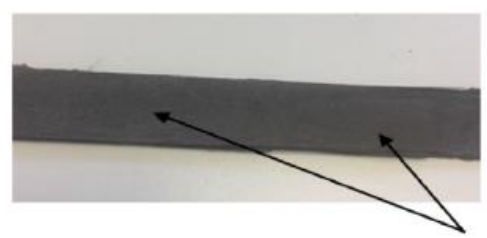

Almost even thickness of a thin layer of IHSSC-CA

(a)

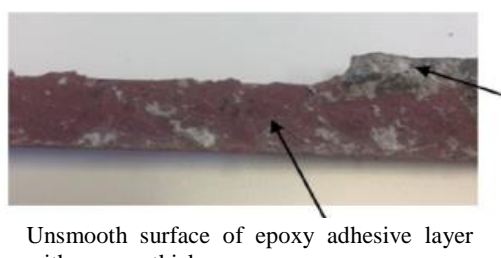
with uneven thickness

(c)

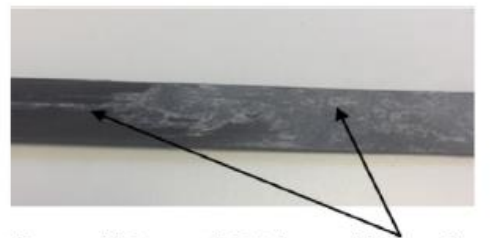

Uneven thickness of PCA layer with a number of voids disturbed randomly

Fig. 4: Pictures of the CFRP strips after pull-out tests (Alyaa et al., 2018; Tareq et al., 2019)

\section{Glass Yam}

Glass yam is the greatest well-known invigorator that is applied in compound manufacturing and there are dissimilar profitable types of it that some of them are as follows: AR, ECR, C, S, E (Lund et al., 2018).

Biochemical complexes of these yam are dissimilar and each one is appropriate for a singular procedure. About 90 out of a hundred of practical yam in engineering complexes is glass yam. Glass yam has a appropriate rigidity, grasp its automatic possessions in high temperatures, has a appropriate moisture and corrosion persistance and is closely inexpensive (Aram et al., 2008).

\section{Results}

Great stability, erosion persistance and electromagnetic impartiality make Fiber Reinforced 
Plastics (FRP) suitable applicants in many suggestions, with association and the development of original memberships. While the application of compound resources has extended expressively over the centuries, its suggestion to civil engineering constructions has been restricted. This education reviews the usage of the fiber as a association physical for physical concrete memberships through frequent new hard work for stability, automatic possessions and flexural consolidation. These times all know the meaning of seisemic enduring of buildings in seisemic-prone regions. With respect to this opinion that obtainable concrete buildings are usually designed and made reagrd on earliest rules without examining the result of seisemic forces and the recent rules don't assess any earthquake, subsequently, these buildings must be perseverance intelligent. Inspection on normal of HPFRCC substantial as one of the greatest suitable limited perseverance events of the concrete buildings participant has understanding ineffectiveness. A methodical prototypical for the extreme available prestress extended in an prior education is tabloid and established with trials; an important clearance between idea and knowledge was originated. Additional instructions, both balanced and new, on the conduct of concrete beams reinforced with precompaction FRP pieces show the better performance of the mixture association and pressure its satisfactory stability, strain and flexibility specifications (Alsaif et al., 2019).

\section{Conclusion}

Researchers have showed that the new HPFRCC material that typically is a concrete with a excessive perseverance with steel, glass, aramid and carbon yam has suitable effeciency quantity with concrete and can increase concrete perseverance frame the lookout of twisted and local as these two other materials. In this education, we effort to difference concretes which one contain of overhead yam frame the lookout of pressing and tonsorial perseverance to produce concrete pieces with great perseverance completely, that at latter principles's receptacle of steel pieces had improved significances of persistent and tonsorial perseverance to make these pieces into other samples.

\section{Acknowledgment}

This research was supported by the Isfahan University of the Technology. We thank our all authors who provided insight and expertise that greatly assisted the research.

\section{Author's Contributions}

All authors contributed to design the study, write and revise the manuscript.

\section{Ethics}

The present Study and ethical aspect were approved by the Isfahan University of the Technology. The present study was approved by the Isfahan University of Technology.

\section{References}

Aldaood, A., M. Bouasker and M. Al-Mukhtar, 2016. Effect of water during freeze-thawcycles on the performance and durability of lime-treated gypseous soil. ColdReg. Sci. Technol., 123: 155-163.

Allen, H.G., 1983. Design of composite steel-concrete structures. L.C.P Yam Surrey University Press.

Alsaif, A., S.A. Bernal, M. Guadagnini and K. Pilakoutas, 2019. Freeze-thaw resistance of steel fibre reinforced rubberised concrete. Constr. Build. Mater., 195: 450-458.

Alyaa, M., N.T.K. Al-Saadi and R. Al-Mahaidi, 2018. Assessing the contribution of the CFRP strip of bearing th eapplied load using near-surface mounted strengthening technique with innovative highstrength selfcompacting cementitious adhesive (IHSSC-CA). Polymers, 10: 66.

Aprianti, S.E., 2017. A huge number of artificial waste material can be Supplementary Cementitious Material (SCM) for concrete production-a review part II. J. Clean. Prod., 142: 4178-4194.

Aram M, Zomorodian S.M.A., Vakili A.H, Vakili A. 2008. Comparison of strength between fiberreinforced concrete for the production of high strength concrete sheets. First International Conference on Seismic Rehabilitation, Tabriz, Iran, Oct. 29 to Nov. 2008.

Atis, C.D., 2013. Accelerated carbonation and testing of concrete made with fly ash. Constr. Build. Mater., 17: 147-152.

Berto, L., A. Saetta and D. Talledo, 2015. Constitutive model of concrete damaged by freeze-thaw action for evaluation of structural performance of $\mathrm{RC}$ elements. Constr. Build. Mater., 98: 559-569.

Bogas, J.A., J. De Brito and D. Ramos, 2016. Freezethaw resistance of concrete produced with fine recycled concrete aggregates. J. Clean Prod., 115: 294-306.

Chehab, A.I., C.D. Eamon, G.J. Parra-Montesinos and T.X. Dam, 2018. Shear testing and modeling of AASHTO Type II prestressed concrete bridge girders. ACI Struct. J., 15: 801-811.

Chen, F. and P. Qiao, 2015. Probabilistic damage modeling and service-life prediction of concrete under freeze-thaw action. Mater. Struct., 48: 2697-2711. 
Dongsheng, Z., M. Mao, S. Zhang and Q. Yang, 2019. Construction and Building Materials.

Hanjari, K.Z., P. Utgenannt and K. Lundgren, 2011. Experimental study of the material and bond properties of frost-damaged concrete. Cem. Concr. Res., 41: 244-254.

Heng-Lei, D., W. Zhou and Z. Wang, 2019. Flexural performance of concrete beams reinforced with FRP bars grouted in corrugated sleeves. Composite Structures, Volume 215,1 May 2019, Pages 49-59.

Islam, M.M., A.K.M. Arifuzzaman, M.T. Alam and M.S Islam, 2018. Durabilitycharacteristics of fly ash blended concrete in marine environment. J. Civ. Eng., 46: 53-68.

Karakurt, C. and Y. Bayazit, 2015. Freeze-thaw resistance of normal and high strength concretes produced with fly ash and silica fume. Adv. Mater. Sci. Eng.

Lawrence, J., 1974. Composite Materials, Academic Press, New York, USA.

Lund, M.S.M., K.K. Hansen, R. Brincker, A.H. Jensen and S.D.R. Amador, 2018. Evaluation of freeze-thaw durability of pervious concrete by use of operational modal analysis. Cem. Concr. Res., 106: 57-64.

Mehta, P.K., 1980. Durability of concrete in marine environment-A review. Spec. Publ., 65: 1-20.

Penttala, V. and F. Al-Neshawy, 2002 .Stress and strain state of concrete during freezing and thawing cycles. Cem. Concr. Res., 32: 1407-1420.
Sirca Jr, G.F. and H. Adeli, 2018. Infrared thermography for detecting defects in concrete structures. J. Civ. Eng. Manage, 24: 508-515.

Tareq, N., K. Al-Saadi, A. Mohammed, R. Al-Mahaidi and J. Sanjayan, 2019. A state-of-the-art review: Near-surface mounted FRP composites for reinforced concrete structures. Construction Building Materials, 209: 748-769.

Wang, W., C. Lu and Y. Li, 2017. Effects of stress and high temperature on the carbonation resistance of fly ash concrete, Constr. Build. Mater., 138: 486-495.

Wang, X. and M. Petru, 2019. Freeze-thaw resistance of epoxy/concrete interface evaluated by a novel wedge splitting test. Constr. Build. Mater., 210: 434-441.

Wenting, L., C. Ling, Z. Jiang and Q. Yu, 2019. Evaluation of the potential use of form-stable phase change materials to improve the freeze-thaw resistance of concrete. Constr. Build. Mater., 203: 621-632.

Yildirim, S.T., C. Meyer and S. Herfellner, 2015. Effects of internal curing on the strength, drying shrinkage and freeze-thaw resistance of concrete containing recycled concrete aggregates. Constr. Build. Mater., 91: 288-296. 